Journal of the Operations Research

Society of Japan

Vol. 22, No. 1, March, 1979

\title{
ON A PREVENTIVE MAINTENANCE WITH MONITORED SYSTEM
}

\author{
Kazuyuki Suzuki \\ Tokyo Institute of Technology
}

(Received June 30, 1978; Revised October 6, 1978)

\begin{abstract}
A monitored system consists of a core system and its monitor. A core system follows a general life time distribution, but its state, good or not good, cannot be observed directly. In order to infer the state of the core system, we use the information from the monitor whose states are stochastically related to the states of the core system. Using its information, we make the maintenance policy for the core system so as to minimize the total expected cost incurred by a sequence of actions. This paper shows the conditions under which an optimal maintenance policy for the above model has the form of a control limit policy. Also, a numerical example where the life time of the system follows a Weibull distubution is presented.
\end{abstract}

\section{Introduction}

Stochastic decision models with complete state observation have been investigated by many authors ([1], [8], [9]), etc.). Derman [3] and Hatoyama [5] formulate the problems as Markovian decision processes (MDP's), and show that an optimal policy has a simple form called a control limit policy under some conditions [6].

Stochastic decision models with uncertain information have also been investigated by several authors ([4], [11], [12], etc.) under the assumption that the internal state of the system is known with certainty by "inspection". Models with uncertain information where inspection does not necessarily reveal the true state of the system are worthwhile to consider in many practical applications. $\mathrm{MDP}^{\prime} \mathrm{s}$ with the above property are often called partially observable Markov processes ([13], [15]), or MDP's with incomplete state observation ([10], [14]). In this paper, however, we use the term monitored system or system with a monitor instead. Here the state of a monitor is observable but it does not describe the state of the system deterministically, but only stochastically. Toward the direction of this approach, Sawaragi and Yoshikawa [14] 
and Renius [10] study the probabilistic properties of the model introducing a set of probability measures. Smallwood and Sondik [15] treat the problem over a finite planning horizon, and Sawaki and Ichikawa [13] investigate $\varepsilon$-optimal solution. But there appears to have been almost no research work discussing the optimality of a solution over an infinite horizon in concrete and practical forms. Besides, in stochastic models with a monitor, they usually assume that the transition probabilities of the system are independent of its age, and general failure distributions such as Weibull distribution are not considered at a11. On the other hand, preventive manitenance systems with a monitor have been developed as "Condition Monitoring System" or "Machine Diagnosis Technique by Censor". Nowadays, monitoring is often necessary and very important for the maintenance of the complex systems such. as aircrafts.

Therefore in this paper, we consider a monitored system where the transition of the states of the system may depend on its age. We show that under some conditions, the optimal policy has the form of a control limit policy.

\section{Model Description of the Monitored System}

Consider a system which takes one of two underlying states - 0 (good) and 1 (failure), these states we call internal states of the coresystem. Its transition from good to failure follows some failure distributions. But we are not permitted to observe the internal state of the core system directly. What we can do is to obtain the information on its internal state from the socalled "monitor", and to infer the internal state from the state of the monitor. We assume that the monitor has a finite number of states and can be always observed, and the states of the monitor are stochastically related to the internal states of the core system. Moreover, the states of the monitor, $\{0,1,2, \cdots, l\}$, are ordered in such a way that a higher number shows a higher probability of a failure of the core system. Observing the states of the monitor, what we must consider is when to replace the core system. If we take action "replace", then the core system is renewed and returns to a good state. On the other hand, if we take action "keep", the core system continues to operate, and the transition of the internal stateoccurs according to its failure distributions. After the transition of the internal state, we observe the state of the monitor to infer the internal state. From this information and the history up to now, we take the next action, and so on. Besides, several kinds of costs are incuxred, depending on the actions to be taken and the internal state of the core system. Hence, the problem is to minimize the total expected cost incurred by a sequence of actions. 
In order to clarify the above model, we make the following definitions, notations, and assumptions.

1) $S=\{0,1\}$ is a set of the internal states of the core system ( 0 means it is in good condition, while 1 implies its failure).

2) $M=\{0,1,2, \cdots, l\}$ is a set of the states of the monitor.

3) $\mathrm{A}=\left\{\mathrm{a}_{0}\right.$ (keep), $\mathrm{a}_{1}$ (replace) $\}$ is a set of actions.

4) $\mathrm{T}=\{0,1,2, \cdots\}$ is a set whose element represents the age of the core system. Here we define a unit of the age (a period) as the time needed for the monitor to censor the internal state of the core system.

5) Transition of the system of age $t$ follows $P(t) \varepsilon \operatorname{Pr}(S \mid S T A), t \varepsilon \cdot T$, where $X Y$ means a Cartesian product of $X$ and $Y$, and $\operatorname{Pr}(X \mid Y)$ is a set of all conditional probabilities on $X$ given $Y$.

6) The state of the monitor is stochastically related to the internal states of the core system. Its conditional probability is given by $Q \varepsilon \operatorname{Pr}(\mathbb{M} \mid S)$.

7) $\phi_{0} \varepsilon \Phi$ is the initial information, where $\Phi$ is a set of the states of the whole system.

8) As costs, we consider a replacement cost $R$, an operating cost $L$ per unit period, and a breakdown cost $D$ per unit period.

If we take action $a_{1}$ (replace), then a replacement cost $R$ is incurred, and a new system with age 0 is installed at the beginning of the next period. If we take action $a_{0}$ (keep), then an operating cost $L$ is charged per unit period. Furthermore, if we take action $a_{0}$ in case the core system has been failed already, then a breakdown cost $D$ is added per unit period (see Table 1).

We assume that all cost, transition probabilities and conditional probabilities are known and that all costs are bounded and non--negative. Furthermore, if the transition probability of the core system can be assumed to be independent of its age $t \varepsilon \mathrm{T}$, the data $\mathrm{H}$ on the whole system, i.e. $\mathrm{H}=$

Table 1. Relations of actions, costs and states

\begin{tabular}{|c|c|c|c|}
\hline \multicolumn{2}{|c|}{ action } & \multicolumn{2}{|c|}{ cost } \\
\hline A & meaning & core state: 0 & core state: 1 \\
\hline $\mathrm{a}_{0}$ & keep & $\mathrm{L}$ & $\mathrm{L}+\mathrm{D}$ \\
\hline $\mathrm{a}_{1}$ & replace & $\mathrm{R}$ & $\mathrm{R}$ \\
\hline
\end{tabular}


ФAMA $\cdots A$ AM is reduced into a posterior probability $g \in G=\operatorname{Pr}(\mathrm{S} \mid \mathrm{H})$ by Bayes' theorem [13]. However in the case where the transition probability depends on $t \varepsilon T$, the above reduction is incomplete and we must take $(g, t) \varepsilon G T \equiv \Phi$ as a state of the whole system. Here we define the posterior probability $g \in G$ as the probability that the core system is in failure.

According to the above definitions, the transition probability $P(t)$ on the internal states of the core system of age $t$ is given by,

$$
P(t)=\left\{\begin{array}{cc}
{\left[\begin{array}{cc}
1-r(t) & r(t) \\
0 & 1
\end{array}\right], \text { if } a_{0} \text { (keep) } \varepsilon A} \\
{\left[\begin{array}{cc}
1 & 0 \\
1 & 0
\end{array}\right], \text { if } a_{1} \text { (replace) } \varepsilon A,}
\end{array}\right.
$$

where (i,j)-th element of $P(t)$ represents $\operatorname{Pr}\left(S_{t+1}=j \mid S_{t}=i\right)$, and $r(t)=$ $1-\exp \left\{-\int_{t}^{t+1} \lambda(u) d u\right\}$, where $\lambda(t)$ is a failure rate of the core system. $S_{t}$ is the internal state of the core system at age $t \varepsilon T . M_{t}, G_{t}$ and $A_{t}$ can be introduced similarly.

Conditional probability $Q$ on the state of the monitor is given by

$$
Q=\left[\begin{array}{llll}
\mathrm{q}_{00} & \mathrm{q}_{01} & \cdots & \mathrm{q}_{0 \ell} \\
\mathrm{q}_{10} & \mathrm{q}_{11} & \cdots & \mathrm{q}_{1 \ell}
\end{array}\right]
$$

where the element $q_{i j}$ represents $\operatorname{Pr}\left(M_{t}=j \mid S_{t}=i\right)$ for any $t \varepsilon T$. Here we assume that $Q$ is independent of the age $t \varepsilon T$ of the system and that the number of states of the monitor is $\ell+1$.

Then if we take action $a_{0}$ (keep) at age $t \varepsilon \mathrm{T}$, using Bayes' theorem, the posterior probability is calculated as

$$
\begin{aligned}
& \operatorname{Pr}\left(S_{t+1}=1 \mid G_{t}=g, A_{t}=a_{0}, M_{t+1}=m\right) \\
= & \frac{\operatorname{Pr}\left(S_{t+1}=1, M_{t+1}=m \mid G_{t}=g, A_{t}=a_{0}\right)}{P_{r}\left(M_{t+1 .}=m \mid G_{t}=g, A_{t}=a_{0}\right)} \\
= & \frac{q_{1 m}\{r(t)(1-g)+g\}}{q_{O m}\{(1-r(t))(1-g)\}+q_{1 m}\{r(t)(1-g)+g\}} \\
\equiv & \frac{B_{m}(g, t)}{A_{m}(g, t)}
\end{aligned}
$$


Also the probability that the monitor shows state $m$ when the age of the core system is $t+1$ is

$$
\begin{aligned}
\operatorname{Pr}\left(M_{t+1}=m \mid G_{t}=g, A_{t}=a_{0}\right) & =q_{0 m}\{(1-r(t))(1-g)\}+q_{1 m}\{r(t)(1-g)+g\} \\
& \equiv A_{m}(g, t)
\end{aligned}
$$

Let $V[g, t]$ denote the total expected cost incurred when an optimal policy is employed, given that the whole system starts in state $(g, t) \varepsilon \Phi$ and future costs are discounted by a factor $\beta$. Then $V[g, t]$ is the unique solution of

$$
\begin{aligned}
V[g, t]= & \min \left\{L+g D+\beta \sum_{m} \sum_{0} V\left[\frac{B_{m}(g, t)}{A_{m}(g, t)}, t+1\right] A_{m}(g, t) ;\right. \\
& R+\beta V[0,0]\} \\
\equiv & \left.\left.\left(\min _{0}, a_{1}\right)\left\{V^{g}\right), t\right] ; V^{\left(a_{1}\right)}[g, t]\right\} .
\end{aligned}
$$

In the next section, we show that if the failure rate $\lambda(t)$ of the core system is IFR, the optimal policy has the form of a control limit policy, and the state space $\Phi$ is divided into two regions. It is remarkable that we need not consider the condition on a conditional probability $Q$ of a monitor. Here we notice that a non-randomized stationary rule is obtained as the unique solution to (2.5), since all costs are bounded and action space is finite [2].

\section{Control Limit Policy with Respect to Monitored System.}

In this section we discuss an optimal maintenance policy for a monitored system. An important and interesting point in preventive maintenance is whether an optimal maintenance policy has a simple form or not. For example, we speak of a control limit policy as the policy where the system is replaced if and only if its condition is worse than some critical value. If an optimal policy is known to possess this simple type of policy, it is very convenient for the maintenance of the system. In the following, we give some conditions under which a control limit policy is optimal.

First we show that under the following Condition 1 , the cost function $\mathrm{V}[\mathrm{g}, \mathrm{t}]$ is a monotone non-decreasing function in both $\mathrm{g}$ and $t$.

\section{Condition 1.}

(a) For any $i, j \quad(0 \leqq i \leqq j \leqq l)$, 


$$
\frac{q_{0 i}}{q_{1 i}} \geq \frac{q_{0 j}}{q_{1 j}}
$$

(b) Failure rate $\lambda(t)$ is IFR (IFR stands for increasing (nondecreasing in strict sense) failure rate).

(c) For any $\mathrm{k} \quad(0 \leq \mathrm{k} \leqq \ell)$,

$$
\sum_{m=k}^{\ell} \mathrm{q}_{1 \mathrm{~m}} \geqq \sum_{\mathrm{m}=\mathrm{k}}^{\ell} \mathrm{q}_{0 \mathrm{~m}} .
$$

Here we notice that Condition 1 (a) implies Condition $L$ (c) (see Appendix). Thus in the following discussion Condition 1 (c) can be omitted from Condition 1 .

Lemma 1. Condition 1 is sufficient for Condition 2 stated below.

Conditior 2.

(a) For $0 \leqq j \leqq \ell, \sum_{m}^{\ell} A_{m}(g, t)$ is monotone non-decreasing in both $g$ and $t(g \varepsilon \quad G, t \varepsilon \quad T)$.

(b) $\frac{B_{m}(g, t)}{A_{m}(g, t)}$ is monotone non-decreasing in $g, t$ and $m$ ( $g \varepsilon G$, $\mathrm{t} \varepsilon \mathrm{T}, \mathrm{m} \varepsilon \mathrm{M})$.

Proof : (i) Condition 1 (b) and 1 (c) are necessary and sufficient for Condition 2(a), since from (2.4),

$$
\begin{aligned}
\sum_{\mathrm{m}}^{\ell} \mathrm{A}_{\mathrm{m}}(g, t) & =\left\{\sum_{\mathrm{m}=\mathrm{j}}^{\ell}\left(\mathrm{q}_{1 \mathrm{~m}}-\mathrm{q}_{0 \mathrm{~m}}\right)\right\}(1-r(t)) \mathrm{g}+\left\{\sum_{\mathrm{m}=\mathrm{j}}^{\ell}\left(\mathrm{q}_{1 \mathrm{~m}}-\mathrm{q}_{0 \mathrm{~m}}\right)\right\} r(t)+\sum_{m=j}^{\ell} \mathrm{q}_{0 m} \\
& =\left\{\sum_{\mathrm{m}=\mathrm{j}}^{\ell}\left(\mathrm{q}_{1 \mathrm{~m}}-\mathrm{q}_{0 \mathrm{~m}}\right)\right\}(1-\mathrm{g}) \mathrm{r}(\mathrm{t})+\left\{\sum_{\mathrm{m}=\mathrm{j}}^{\ell}\left(\mathrm{q}_{1 \mathrm{~m}}-\mathrm{q}_{0 \mathrm{~m}}\right)\right\} \mathrm{g}+\sum_{\mathrm{m}=\mathrm{j}}^{\ell} \mathrm{q}_{0 \mathrm{~m}},
\end{aligned}
$$

and $0 \leqq g \leqq 1,0 \leqq r(t) \leqq l$. The proof immediately follows.

(ii) Condition $1(a)$ and $1(b)$ are sufficient for Condition $2(b)$. Since from property $0 \leqq \mathrm{q}_{0 \mathrm{~m}} \leqq 1,0 \leqq \mathrm{r}(\mathrm{t}) \leqq 1(0 \leqq \mathrm{~m} \leqq l, t=0,1, \cdots)$, and the derivative of $r(t)\left(\frac{d}{d t} r(t)=\exp \left\{-\int_{t}^{t+1} \lambda(u) d u\right\}(\lambda(t+1)-\lambda(t))\right)$, we can easily prove that the partial derivative or differences of $\frac{B_{m}(g, t)}{A_{m}(g, t)}$ with respect to $g$, $t$ and $m$ are a1l non-negative under Condition $1(a)$ and $1(b)$. For example, with respect to $m \quad(0 \leqq i \leqq j \leqq \ell)$, 


$$
\begin{aligned}
& \frac{B_{j}(g, t)}{A_{j}(g, t)}-\frac{B_{i}(g, t)}{A_{i}(g, t)} \\
& =\frac{\{r(t)(1-g)+g\}\left(q_{0 i} q_{1 j}-q_{0 j} q_{1 i}\right)(1-g)(1-r(t))}{\left[q_{0 j}\{(1-r(t))(1-g)\}+q_{1 j}\{r(t)(1-g)+g\}\right]\left[q_{0 i}\{(1-r(t))(1-g)\}+q_{1 i}\{r(t)(1-g)+g\}\right]} . \\
& \text { Thus if } q_{0 i} q_{1 j}-q_{0 j} q_{1 i} \geqq 0 \text {, i.e. } \frac{q_{0 j}}{q_{1 i}} \geqq \frac{q_{0 j}}{q_{1 j}} \text {, then } \frac{B_{j}(g, t)}{A_{j}(g, t)} \geqq \frac{B_{i}(g, t)}{A_{i}(g, t)} \\
& (0 \leqq i \leqq j \leqq \ell) \\
& \text { From (i) and (ii), the result is obtained. } \\
& \sum_{m}^{\ell} A_{m}(g, t) V_{m}[g, t]
\end{aligned}
$$

is also monotone non-decreasing in $g$ and $t$.

Proof : From $A_{m}(g, t) \geqq 0$ and Abel's identity,

$$
\begin{aligned}
& \text { (3.1) } \frac{\partial}{\partial g}\left\{\sum_{m=0}^{\ell} A_{m}(g, t) V_{m}[g, t]\right\}=\sum_{m=0}^{\ell}\left\{\frac{\partial}{\partial g} A_{m}(g, t)\right\} V_{m}[g, t]+\sum_{m=0}^{\ell} A_{m}(g, t)\left\{\frac{\partial}{\partial g} V_{m}[g, t]\right\} \\
& \geq \sum_{m=0}^{l}\left\{\frac{\partial}{\partial g} \quad A_{m}(g, t)\right\} \quad V_{m}[g, t] \\
& =\sum_{m=0}^{l}\left\{\frac{\partial}{\partial \vec{g}} A_{m}(g, t)\right\} V_{0}[g, t] \\
& +\sum_{m=1}^{\ell} \frac{\partial}{\partial g} A_{m}(g, t)\left\{v_{1}[g, t]-v_{0}[g, t]\right\} \\
& +\cdots \\
& +\sum_{m=\ell}^{\ell}\left\{\frac{\partial}{\partial g} A_{m}(g, t)\right\}\left\{v_{\ell}[g, t]-v_{\ell-1}[g, t]\right\}
\end{aligned}
$$

Thus from Condition $2(a), v_{0}[g, t] \geqq 0$ and the monotonicity of $V_{m}[g, t]$ in $m$,

$$
\frac{\partial}{\partial g}\left\{\sum_{m=0}^{\ell} A_{m}(g, t) v_{m}[g, t]\right\} \geqq 0 .
$$

By the similar argument we can show that 


$$
\sum_{m=0}^{\ell} A_{m}(g, t+1) v_{m}[g, t+1]-\sum_{m=0}^{\ell} A_{m}(g, t) v_{m}[g, t] \geq 0,
$$

yielding the second part of the lemma.

Lemma 3. Under Condition 2, $V[g, t]$ is monotone non-decreasing in both $g$ and $t$.

Proof: The proof is by induction. Let $v^{n}[g, t]$ denote the optimal $n-$ period cost. Then,

$$
\begin{aligned}
& \mathrm{V}^{1}[g, t]=\min \{L+g D ; R\}, \\
& V^{n}[g, t]=\min \left\{L+g D+\beta \sum_{m=0}^{\ell} V^{n-1}\left[\frac{B_{m}(g, t)}{A_{m}(g, t)}, t+1\right] A_{m}(g, t) ;\right. \\
& \left.R+\beta V^{n-1}[0,0]\right\}, \quad(n \geq 2) .
\end{aligned}
$$

For $\mathrm{n}=1, \mathrm{v}^{1}[\mathrm{~g}, \mathrm{t}]$ is monotone non-decreasing in $g$ and $t$. If $\mathrm{V}^{\mathrm{n}-1}[\mathrm{~g}, \mathrm{t}]$ is monotone non-decreasing in $g$ and $t$, then under condition $2(b), v^{n-1}\left[\frac{B_{m}(g, t)}{A_{m}(g, t)}\right.$, $t+1]$ is monotone non-decreasing in $g, t$ and $m$. Further, this value is non-negative since all costs are non-negative. Here $\mathrm{V}_{\mathrm{m}}[\mathrm{g}, \mathrm{t}]$ in Lemma 2 corresponds to $v^{n-1}\left[\frac{B_{m}(g, t)}{A_{m}(g, t)}, t+1\right]$. Then from Lemma 2 and $(3.2), v^{n}[g, t]$ is monotone non-decreasing in $g$ and $t$. This holds for all $n$, and as

$$
\lim _{n \rightarrow \infty} v^{n}[g, t]=v[g, t],
$$

$\mathrm{V}[\mathrm{g}, \mathrm{t}]$ is monotone non-decreasing in $\mathrm{g}$ and $\mathrm{t}$.

Here we notice that the condition on a monitor, $\frac{{ }^{q_{0 i}}}{{ }_{q_{1 i}}} \geq \frac{{ }^{q_{0 j}}}{q_{1 j}}(0 \leqq i \leq j \leq \ell)$, can be obtained by rearranging the states of a monitor in such a way that $\frac{\mathrm{q}_{0 \mathrm{~m}}}{\mathrm{q}_{1 \mathrm{~m}}}$ is in the decreasing order, and by giving the name 'state $j$ ' to the $j$-th state after the arrangement, say $i_{j}$, for each $j$. Nothing in the proof of the above lemma can be disturbed by the reordering of the states. Therefore above condition on a monitor always holds for any cases. So in practice, we need only Condition $1(\mathrm{~b})$ on the life time distribution of a core system. Then next theorem can be obtained.

Theorem. If a failure rate $\lambda(t)$ of a core system is IFR, then an optimal 
policy has the form of a control limit policy, and the state space $\Phi$ is divided into at most two regions.

Proof : From (2.5)

$$
\mathrm{V}^{\left(\mathrm{a}_{1}\right)}[\mathrm{g}, \mathrm{t}]=\mathrm{R}+\beta \mathrm{V}[0,0] \text {, }
$$

which is constant for any $g$ and $t$. Hence by the monotonicity of $V[g, t]$ the theorem is obtained.

Therefore three cases will happen on the partition of the state space $\Phi$ (see Fig. 1).

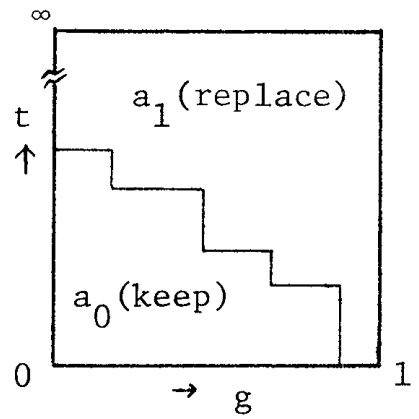

(a) Two regions

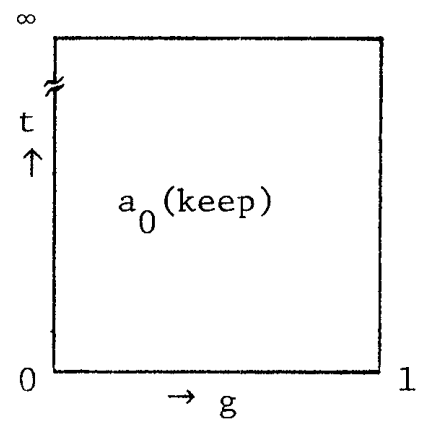

(b) One region

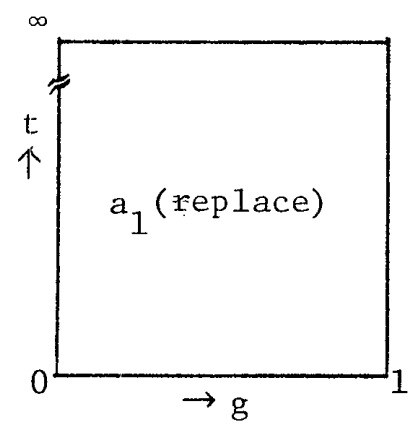

(c) One region

Fig. 1 Three types of control limit policies

The following discussion is devoted to present a necessary or a sufficient condition for each of the above three cases.

\section{Remarks.}

1.1 If $R>L+D$, then an optimal action for $(0,0) \varepsilon \Phi$ is $a_{0}$ (keep).

1.2 If $\frac{L+D}{1-\beta}>R+\beta V[0,0]$, then an optimal action for $(1, \infty) \varepsilon \Phi$ is $a_{1}$ (replace).

2.1 [1 region, keep is always optima1 ] $\mathrm{a}_{0}$ (keep) is always optimal if $\mathrm{R}>\mathrm{L}$ and $\mathrm{D}=0$. Under this condition, the objective function is given by

$$
V[g, t]=\frac{L}{1-\beta} \text {, }
$$


for any $(g, t) \varepsilon \Phi$

2.2 [1 region, replace is always optimal]

$a_{1}$ (replace) is always optimal if and only if $R \leqq L$.

Furthermore in this case, the objective function is given by

$$
\mathrm{V}[\mathrm{g}, \mathrm{t}]=\frac{\mathrm{R}}{\mathrm{I}-\beta} \text {, }
$$

for any $(g, t) \varepsilon \Phi$.

2.3 [2 regions, necessary condition]

$\mathrm{R}>\mathrm{L}$ and $\mathrm{D} \neq 0$ is a necessary condition for that the state space $\Phi$ j.s divided into two regions.

2.4 [2 regions, sufficient condition]

The state space $\Phi$ is divided into two regions if $R>L+D$ and $\frac{L+D}{1-\beta}>R+\beta V[0,0]$.

Proof and comments are given in appendix. Thus, only in the case where the conditions in Remark 2.3 or 2.4 hold, we need to solve equation (2.5) to find an optimal policy.

\section{Numerical example}

Equation (2.5) is easily solved by the policy iteration technique [7]. Consider the case where the life time of a system follows the Weibul1 distribution with a failure rate $\lambda(t)=\frac{m}{\alpha} t^{m-1}(t>0), i . e \cdot, r(t)=1-\exp \left[-\frac{1}{\alpha}\left\{(t+1)^{\mathfrak{m}}-t^{\mathrm{m}}\right\}\right]$. We set the values of the parameters of the monitored system in the following,

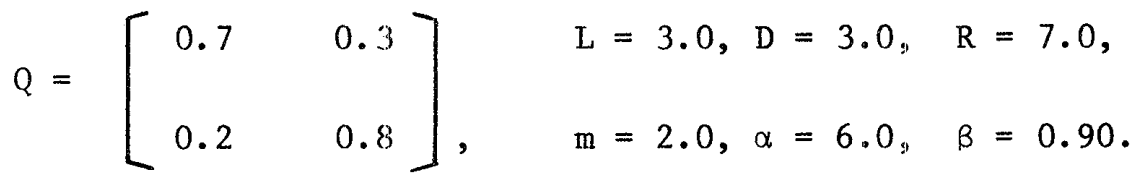

In this case the condition of Theorem is satisfied, and an optimal policy has the form of a control limit policy with two regions as in Fig. 2 .

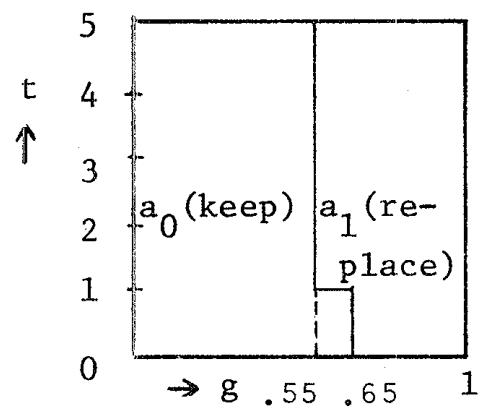

Fig. 2 Numerical example of a control 1imit policy 


\section{Concluding Remark}

In this paper, we show the condition under which an optimal maintenance policy has the form of a control limit policy. It is noticeable that the condition on the conditional probabilities of a monitor, $\frac{q_{0 i}}{q_{1 i}} \geq \frac{q_{0 j}}{q_{1 j}}(0 \leqq i \leq j \leq l)$, can be neglected by reordering the states of a monitor. So in case where a core system has two states, the condition we must consider is only on a failure rate $\lambda(t)$ of the core system. But some conditions on a monitor would be required for the ordering of the states of a monitor where a core system has more than two states, which will be a future topic to be studied.

\section{Acknowledgements}

I sincerely thank Professor H. Makabe and Dr. Y. Hatoyama for their helpful suggestions and guidance throughout this paper. I also wish to acknowledge the referees for their valuable comments and suggestions to improve this paper.

\section{Appendix}

A.1 Proof that Condition 1(a) is sufficient for Condition 1(c):

$$
\begin{aligned}
& \text { As } q_{i j}(i=0,1,0 \leqq j \leqq \ell) \text { is an element of a probability matrix, } \\
& \sum_{\mathrm{m}=0}^{\ell} \mathrm{q}_{0 \mathrm{~m}}=\sum_{\mathrm{m}=0}^{\ell} \mathrm{q}_{1 \mathrm{~m}}=1, \quad 0 \leqq \mathrm{q}_{\mathrm{ij}} \leqq 1 .
\end{aligned}
$$

Hence the following inequality

$$
\frac{\mathrm{q}_{00}}{\mathrm{q}_{10}} \geq \frac{\mathrm{q}_{01}}{\mathrm{q}_{11}} \geqq \cdots \geq \frac{\mathrm{q}_{0 l}}{\mathrm{q}_{1 \ell}}
$$

is transformed into

$$
\frac{1-\sum_{m=1}^{\ell}{ }^{q_{0 m}}}{1-\sum_{m=1}^{\ell} q_{1 m}} \geq \frac{q_{01}}{q_{11}} \geqq \cdots \geqq \frac{q_{0 \ell}}{q_{1 l}},
$$

by the substitutions $\mathrm{q}_{00}=1-\sum_{\mathrm{m}=1}^{\ell} \mathrm{q}_{0 \mathrm{~m}}, \mathrm{q}_{10}=1-\sum_{\mathrm{m}=1}^{\ell} \mathrm{q}_{1 \mathrm{~m}}$. 
The result then follows from straightforward algebraic manipulations of the above inequality.

A.2 Proof of Remarks:

Remarks 1.1 and 1.2 can be easily obtained from (2.5).

(i) Proof of Remark 2.1: From $D=0$ and (2.5),

$$
\mathrm{V}[1, \infty] \leq L+\beta \mathrm{V}[1, \infty]
$$

$$
\text { i.e. } v[1, \infty] \leqq \frac{L}{1-\beta}
$$

Now as $R>L+D \quad(D=0)$, $a_{0}$ (keep) is optimal for $(0,0) \varepsilon \Phi$ by Remark 1.1 . By the monotonicity of $V$,

$$
\begin{aligned}
\mathrm{V}[0,0] & \geqq \mathrm{L}+\beta \sum_{\mathrm{m}=0}^{\ell} \mathrm{V}\left[\frac{\mathrm{B}_{\mathrm{m}}(0,0)}{\mathrm{A}_{\mathrm{m}}(0,0)}, 1\right] \mathrm{A}_{\mathrm{m}}(0,0) \\
& \geqq \mathrm{L}+\beta \mathrm{V}[0,0], \\
\text { or } \mathrm{V}[0,0] & \geqq \frac{\mathrm{L}}{1-\beta} .
\end{aligned}
$$

Therefore,

$$
\frac{L}{1-\beta} \leqq V[0,0] \leqq V[1, \infty] \leqq \frac{L}{1-\beta}
$$

Thus for any $(g, t) \varepsilon \Phi$,

$$
\mathrm{V}[g, t]=\frac{\mathrm{L}}{1-\beta}
$$

(ii) Proof of Remark 2.2 :

(necessary condition) If $a_{1}$ (replace) is always optimal, then

for any $(g, t) \varepsilon \Phi$,

$$
\mathrm{V}[\mathrm{g}, \mathrm{t}]=\mathrm{R}+\beta \mathrm{V}[0,0] \text {. }
$$

Thus for $(g, t)=(0,0)$,

$$
\begin{aligned}
V[0,0] & =R+\beta V[0,0], \\
\text { i.e. } V[0,0] & =\frac{R}{1-\beta} .
\end{aligned}
$$

Therefore, for any $(g, t) \varepsilon \Phi$,

$$
\mathrm{V}[\mathrm{g}, \mathrm{t}]=\mathrm{R}+\beta \mathrm{V}[0,0]=\frac{\mathrm{R}}{1-\beta} \text {. }
$$


Now from $(2.5)$,

$$
\begin{aligned}
\mathrm{v}^{\left(\mathrm{a}_{0}\right)}[\mathrm{g}, \mathrm{t}] & =\mathrm{L}+\mathrm{gD}+\beta \sum_{\mathrm{m}=0}^{\ell}\left(\frac{\mathrm{R}}{1-\beta}\right) \mathrm{A}_{\mathrm{m}}(0,0) \\
& =\mathrm{L}+\mathrm{gD}+\beta \frac{\mathrm{R}}{1-\beta}, \\
\mathrm{V}^{\left(\mathrm{a}_{1}\right)}[\mathrm{g}, \mathrm{t}] & =\mathrm{R}+\beta \frac{\mathrm{R}}{1-\beta} .
\end{aligned}
$$

If $a_{1}$ (replace) is always optimal, then for any $(g, t) \varepsilon \Phi$,

$$
v^{\left(a_{0}\right)}[g, t] \geqq v^{\left(a_{1}\right)}[g, t] .
$$

must hold. Hence $L+g D \geqq R$ must hold for any $g \in[0,1]$. Therefore if $\mathrm{a}_{1}$ (replace) is always optimal, then $\mathrm{L} \geqq \mathrm{R}$.

(sufficient condition) The result can be easily obtained from (2.5) and by the monotonicity of $\mathrm{V}$.

Remark 2.3 follows from the contrapositive of Remark 2.1 and the negation of the condition in Remark 2.2. And Remark 2.4 is obtained from Remarks 1.1 and 1.2 .

\section{References}

[1] Barlow, R. E., Proschan, F. and Hunter, L.: Mathematical Theory of Reliability. John Wiley, New York, 1965.

[2] Blackwe11, D.: Discounted Dynamic Programming. Annals of Mathematical Statistics, Vo1. 36(1965), 226-235.

[3] Derman, C.: On Optimal Replacement Rules when Changes of State are Markovian. Mathematical Optimization Techniques (ed. R. Bellman). University of California Press, Berkeley, 1963, 201-210.

[4] Girshick, M. A. and Rubin, H: A Bayes' Approach to a Quality Contro1 Mode1. Annals of Mathematical Statistics, Vo1. 23(1952), 114-125.

[5] Hatoyama, Y.: Markov Maintenance Mode1s with Control of Queue. Joumal of the Operations Research Society of Japan, Vo1. 19(1977), 164-181.

[6] Hatoyama, Y.: Mathematics of Reliability (3). Communications of the Operations Research Society of Japan, Vo1. 23(1978), 44-49.

[7] Howard, R. A.: Dynamic Programming and Markov Processes. Technology Press \& John Wiley, New York, 1960. 
[8] Jorgenson, D. W., McCa11, J. J. and Radner, R.: Optimal Replacement Policy. North-Ho1land Publishing Company, Amsterdam, 1967.

[9] Morimura, H. and Makabe, H.: On Some Preventive Maintenance Policies. Jourmal of the Operations Research Society of Japan, Vo1. 6(1963), 17-47.

[10] Rhenius, D.: Incomplete Infoxmation in Markovain Decision Models. The Annals of Statistics, Vol. 2(1974), 1327-1334.

[11] Rosenfield, D.: Markovian Deterioration with Uncertain Information - A More General Model. Naval Research Logistics Quarterly, Vol. 23(1976), 389-405.

[12] Ross, S. M.: Quality Control Under Markovian Deterioration. Management Science, Vo1. 17(1971), 694-706.

[13] Sawaki, K. and Ichikawa, A.: Optimal Control for Partially Observable Markov Decision Processes over an Infinite Horizon. Joumal of the Operations Research Society of Japan, Vol. 21(1978), 1-16.

[14] Sawaragi, Y. and Yoshikawa, T.: Discrete-time Markovian Decision Processes with Incomplete State Observation. The Annals of Mathematical Statistics, Vo1. 41(1970), 78-86.

[15] Smollwood, R. D. and Sondik, E. J.: The Optimal Control of Partially Observable Markov Processes over a Finite Horizon, Operations Researeh, Vo1. 21(1973), 1071-1088.

Kazuyuki SUZUKI : Department of Management Engineering, Tokyo Institute of Technology, 0-okayama, Meguro-ku Tokyo, 152, Japan. 
状態監視保全に関する一考察

東京工業大学 鈴 木 和 幸

本論文は, 従来の時間計画保全に対して, 近年導入された状態監視保全 (monitored ma intenance) に関し, 論じたものである。今, ある装置を考える。この装置 (以下 “本体”と呼ぶ) の稼働 状態は外部からは直接把握することは出来ず, “モニター”と呼ばれる状態監視装置からの情報に基 づき本体の状態を推測する。本体は，正常又は故障の 2 状態をとり，その遷移は故障率入(t)をもつ 寿命分布に従うすのとする。一方，モニターは $(\ell+1)$ 個の状態をとり，その状態は，本体の状態の条 件付確率, 即ち, 次の確率行列によって規定されるものとする,

$$
\mathrm{Q}=\left[\begin{array}{lllll}
q_{00} & q_{01} & \cdots & \cdots & q_{0 \ell} \\
q_{10} & q_{11} & \cdots & \cdots & q_{1 \ell}
\end{array}\right],
$$

ただし， $q_{\mathrm{ij}}$ は本体が状態 $\mathrm{i}(0$ ( 正常)，1（故障）)にあるときにモ二ターが状態主とる確率である。 本体の状態遷移確率が本体の稼働時間 $\mathrm{t} \in \mathrm{T}$ 亿独立な場合は, Partially Observable Markov Decision Processes として有限期間問題, $\varepsilon$-optimal 解等が研究されている。しかし, 稼働時 間を考慮し，無限期間問題を具体的・実用的な形で取扱ったものはみられない。そこで本論文では上 記の点を考慮しモデル化を行なった。な报,アクションとして $\{$ keep , r eplace \}, 目的函数とし て総期待費用を考えた。

本論文のモデルに括いては, ベーズの定理による事後確率 $\mathrm{G}$ と本体の稳働時間 $\mathrm{T}$ の直皘集合 $\mathrm{G} ・ \mathrm{~T}$ ”Фに過去の履歴が縮約されこののを用いて，最適保全方式に従った場合の総期待費用に関する関 数方程式が得られる。この式に基づき，次の条件が成り立つとき，最適保全方式は，状態空間 々 2 分割されるコントロールリミットポリンーによって与えられることが示される。

条件 (a) $\frac{q_{0 \mathrm{i}}}{q_{1 \mathrm{i}}} \geqq \frac{q_{0 \mathrm{j}}}{q_{1 \mathrm{j}}} \quad(0 \leqq \mathrm{i} \leqq \mathrm{j} \leqq \cdots \cdots \cdots)$,

(b) 本体の故障率 $\lambda(\mathrm{t})$ が I F R。

な拉，条件(a)は，モニターの状態の並へ換えにより満たされ，条件(b)の入(t)に関する条件のみが 必要となる。最後に本体の寿命がワイブル分布に従う場合の計算例が与えられている。 